\title{
Pedigree and SSR Data Analysis Reveal Dominant Prevalence of Few Parents in Pedigrees of Pakistani Wheat Varieties
}

\author{
Muhammad Sajjad ${ }^{*}$, Sultan Habibullah Khan'2, Rizwana Maqbool ${ }^{3}$ \\ ${ }^{1}$ Department of Environmental Sciences, COMSATS Institute of Information Technology, Vehari, Pakistan \\ ${ }^{2}$ Center for Agricultural Biochemistry and Biotechnology, University of Agriculture, Faisalabad, Pakistan \\ ${ }^{3}$ Department of Crop and Soil Sciences, Washington State University, Pullman, USA \\ Email: ${ }^{\text {msajjadpbg@gmail.com }}$
}

Received 10 December 2014; revised 2 January 2015; accepted 12 January 2015

Copyright (C) 2015 by authors and Scientific Research Publishing Inc.

This work is licensed under the Creative Commons Attribution International License (CC BY).

http://creativecommons.org/licenses/by/4.0/

(c) (i) Open Access

\section{Abstract}

The international recognition of the importance of genetic diversity demands continuous estimation of genetic diversity of in hand population as test of its buffering capacity against all putative threats. Randomly selected Pakistani wheat varieties developed during 1965-1999 and 2000-2011 were evaluated on the basis of pedigree and SSR data. At $2^{\text {nd }}$ and $3^{\text {rd }}$ levels of pedigree, average occurrence of a parent per variety was 2.1 times. The dominating parents included BLUEBIRD, KALYANSONA and SIETE-CERROS-66, which were present in the pedigrees of $71.42 \%, 64.28 \%$, and $58.57 \%$ varieties, respectively. The varieties INQLAB-91 and KIRAN-95 had the same pedigree and were genetically identical as revealed by SSR data. Similarly, varieties PAVON-76 and SOGHAT-90 also had the same parents in their pedigrees. This genetic similarity was also confirmed by SSR based cluster. The SSR based PC1 and PC2 showed narrow genetic diversity confirming the presence of few dominating parents. The results emphasize the inclusion of novel and genetically diverse parents in Pakistani wheat breeding programs to maintain broader genetic base of varieties/cultivars for buffering the effects of ever changing virulent pathogens and crop growth environments.

\section{Keywords}

Genetic Diversity, Pedigrees, SSR, Wheat

\section{Introduction}

Genetic diversity providing the basic substrate for evolution is very important for the long-standing survival of

${ }^{*}$ Corresponding author.

How to cite this paper: Sajjad, M., Khan, S.H. and Maqbool, R. (2015) Pedigree and SSR Data Analysis Reveal Dominant Prevalence of Few Parents in Pedigrees of Pakistani Wheat Varieties. American Journal of Molecular Biology, 5, 1-6. 
species and their ability to adapt to ever-changing environments [1]. Drastic loss of genetic diversity can result in decreased fitness, imbalance in biodiversity of an ecosystem, lack of evolution and ultimately premature extinction of a population/specie. Genetic diversity can be measured at three levels: 1) within breeding populations; 2) between breeding populations within any one geographic area; and 3) within species. In a breeding population, genetic diversity provides a mechanism for populations to adapt to their changing environment. The more variation, the better the chance that at least some of the individuals will have an allelic variant that is suited for the new environment. The allelic variant suited to the changed environment will produce offspring with the genetic constitution that will in turn reproduce and continue population into subsequent generations.

Major factors causing reduction in genetic diversity include genetic drift, founder effect, demographic bottleneck and inbreeding. In addition to these, objectives oriented breeding, artificial selection, isolation, and replacement of low yielding landraces with high-yielding uniform varieties had reduced the total genetic characteristics of cultivated germplasm and increased dependence on farm inputs, thus polluting the agro-ecosystems.

Genetic diversity in wheat breeding populations has been estimated on the basis of pedigree data [2], morphological data [1], gluten protein data [3]-[6] and molecular markers data [7].

Utilization of few similar parents having similar pedigree in the development of transgressed generations leading to the development of crop cultivars in a specific region has been reported as an important factor of reduced genetic diversity. Therefore, estimation of the pedigree-based distance between cultivar has provided useful insight in the germplasm [8]-[10]. Soleimani et al. [10] traced the ancestry of Canadian cultivars back to 125 cultivars including selections, breeding lines and land races, and estimated pedigree wise distance between the cultivars. Various studies have also indicated positive correlation between the molecular and pedigree based genetic diversity [8] [9]. Additionally, some researchers reported that sufficient genetic diversity was present in Pakistani wheat germplasm implying that the genotypes included had broad genetic base [3] [11] [12]. Based on these reports, the present study was designed to test the following hypothesis.

1) Null hypothesis $\left(\mathrm{H}_{0}\right)$ : Parents in the pedigree of Pakistani wheat varieties are randomly used.

Alternate hypothesis $\left(\mathrm{H}_{1}\right)$ : Parents in the pedigree of Pakistani wheat varieties are not randomly used.

2) Null hypothesis $\left(\mathrm{H}_{0}\right)$ : Pakistani wheat varieties have substantially broad genetic base.

Alternate hypothesis $\left(\mathrm{H}_{1}\right)$ : Pakistani wheat varieties have not substantially broad genetic base.

3) Null hypothesis $\left(\mathrm{H}_{0}\right)$ : Simple sequence repeats (SSR) and pedigree data provide similar pattern of genetic diversity.

Alternate hypothesis $\left(\mathrm{H}_{1}\right)$ : SSR and pedigree data do not provide similar pattern of genetic diversity.

\section{Materials and Methods}

Pedigree information of randomly selected Pakistani wheat varieties was retrieved from CIMMYT wheat data base (link). The pedigree abbreviations were decoded with CIMMYT standard catalogues. The first level pedigree information was organized in excel sheet and percent contribution of each parent in $2^{\text {nd }}$ and $3^{\text {rd }}$ level pedigree to Pakistani wheat varieties included in the study was calculated. The term progenitor was used for exact number of parents in the pedigree and the term parent was used for types of parents in the pedigree of a variety. For example in the $2^{\text {nd }}$ level pedigree of SEHER-06, there are 15 progenitors and 13 parents because BLUEBIRD and KALYANSONA are repeated two times (Figure 1). For pedigree analysis 22 and 14 varieties released between the years 1965-1999 and 2000-2011, respectively, were randomly selected. For SSR analysis DNA from a fresh leaf of each variety was extracted following the method described by Rogowsky et al., [13]. The PCR profile for each SSR primer pair was the same as reported in GrainGene (http://wheat.pw.usda.gov). PCR products were analyzed in 2.5\% high resolution agarose gel according to manufacturer's instructions (Figure 2). Data from 30 polymorphic SSR markers were used for principal component analysis using the software STATISTICA [14].

\section{Results and Discussion}

The pedigree record of 22 varieties released between the years 1965 and 1999 there were a total of 274 progenitors and 152 parents at $2^{\text {nd }}$ and $3^{\text {rd }}$ level pedigree. The progenitors to parents' ratio was 1.80 that ideally would be 1. The progenitors to parents' ratio of 1 means there is no repetition of any parent in the pedigree of a variety. From these 274 progenitors and 152 parents 85 and 10, respectively, were repeatedly used and hence were dominant in the pedigrees of selected varieties. The ratio of dominant progenitors to dominant parents was 8.5 


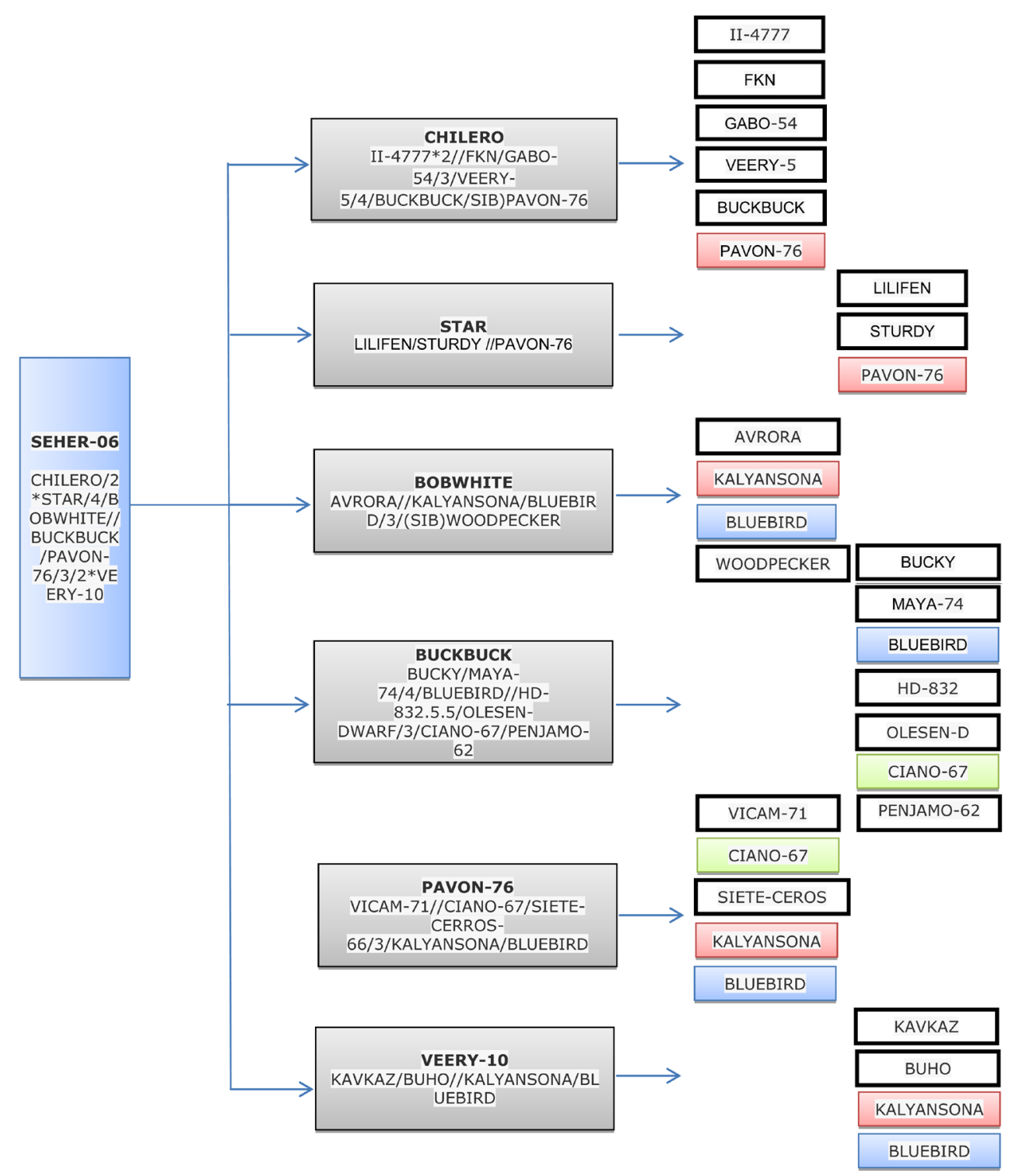

Figure 1. Pedigree record of SEHER-06 showing repetition some parents in $2^{\text {nd }}$ and $3^{\text {rd }}$ level pedigree.

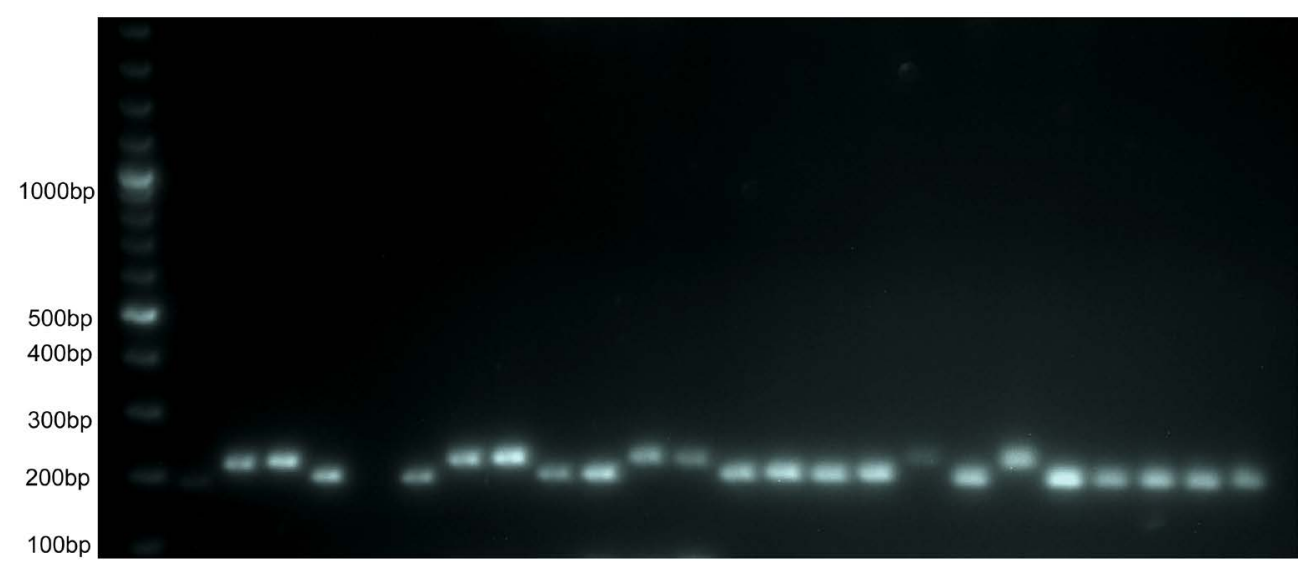

Figure 2. PCR amplification profile of BARC 45 showing the range of alleles in 24 genotypes. 
showing that the average use of each of 10 dominant parents was used 8.5 times in $2^{\text {nd }}$ and $3^{\text {rd }}$ level of pedigrees only (Table 1). The varieties released between 2000 and 2011 had 214 progenitors and 93 parents with progenitor to parents ratio of 2.3. The ratio of dominant progenitors to dominant parents was 6.6 (Table 1). The results showed the repetition of parents at $2^{\text {nd }}$ and $3^{\text {rd }}$ level of pedigree increased from 1.8 before the year 2000 to 2.3 after 2000, however, the repetition of dominant parents decreased from 8.5 to 6.6, respectively. Further, the number of repetitive parents increased after the year 2000.

Though the dominant parents used between 1965-1999 and 2000-2011 were mostly common but their use in the pedigrees changed significantly. Top three dominant parents between 1965-1999 were LERMA-ROJO, GABO-55 and BERVOR, which were repeatedly used in the $2^{\text {nd }}$ and $3^{\text {rd }}$ level pedigrees of $65.45 \%, 60.90 \%$ and 49.09\% varieties, respectively. During the years 2000-2011, the most used parents were BLUEBIRD (71.42\%), KALYANSONA (64.28\%) and SIETE-CERROS-66 (58.57\%). Thus the post 2000 era can be called as BLUEBIRD-KALYANSONA era. Interestingly, PITIC was used as a dominant parent in $13.13 \%$ varieties but was not used in post 2000 varieties (Table 2). The varieties INQLAB-91 and KIRAN-95 had same pedigree and were genetically identical as revealed by SSR data. Similarly, varieties PAVON-76 and SOGHAT-90 had also same parents in their pedigrees. This genetic similarity was also confirmed by SSR based cluster.

Table 1. Basic description of pedigree record of Pakistan wheat varieties.

\begin{tabular}{|c|c|c|c|c|c|c|c|}
\hline Year of releases & $\begin{array}{l}\text { No. of } \\
\text { randomly } \\
\text { selected } \\
\text { varieties }\end{array}$ & $\begin{array}{l}\text { Total no. of } \\
\text { progenitors in } \\
2^{\text {nd }}, 3^{\text {rd }} \text { level } \\
\text { of pedigree }\end{array}$ & $\begin{array}{c}\text { Total no. of } \\
\text { parents in } 2^{\text {nd }} \\
3^{\text {rd }} \text { level of } \\
\text { pedigree }\end{array}$ & $\begin{array}{l}\text { Progenitors } \\
\text { to parent } \\
\text { ratio }\end{array}$ & $\begin{array}{c}\text { Total no. of } \\
\text { dominant } \\
\text { progenitors in } 2^{\text {nd }}, \\
3^{\text {rd }} \text { level of pedigree }\end{array}$ & $\begin{array}{l}\text { Total no. of } \\
\text { dominant parents } \\
\text { in } 2^{\text {nd }}, 3^{\text {rd }} \text { level } \\
\text { of pedigree }\end{array}$ & $\begin{array}{c}\text { Dominant } \\
\text { Progenitors } \\
\text { to dominant } \\
\text { parent ratio }\end{array}$ \\
\hline Between 1965-1999 & 22 & 274 & 152 & 1.80 & 85 & 10 & 8.5 \\
\hline Between 2000-2011 & 14 & 214 & 93 & 2.30 & 66 & 10 & 6.6 \\
\hline
\end{tabular}

Table 2. Basic description of pedigree record of Pakistan wheat varieties.

\begin{tabular}{|c|c|c|c|c|c|c|c|c|c|c|}
\hline Year of releases & KALYANSONA & BLUEBIRD & GABO-55 & PITIC & INIA & BUHO & KAVKAZ & $\begin{array}{c}\text { SIETE } \\
\text { CERROS-66 }\end{array}$ & $\begin{array}{c}\text { LERMA } \\
\text { ROJO }\end{array}$ & BERVOR \\
\hline Between 1965-1999 & 18.18 & 18.18 & 60.90 & 13.63 & 13.13 & 9.09 & 9.09 & 31.81 & 65.45 & 49.09 \\
\hline Between 2000-2011 & 64.28 & 71.42 & 14.28 & 0.00 & 28.57 & 28.75 & 50.00 & 58.57 & 21.42 & 7.14 \\
\hline
\end{tabular}

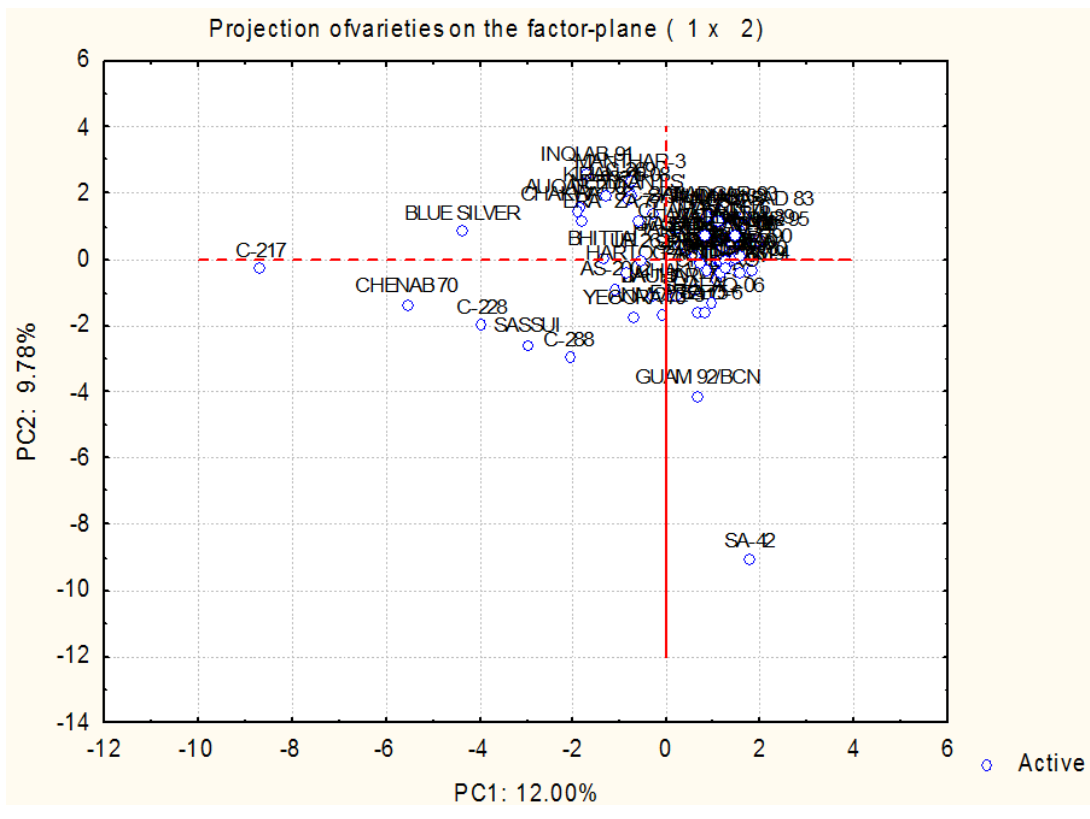

Figure 3. PCA scatter plot based on SSR data. 


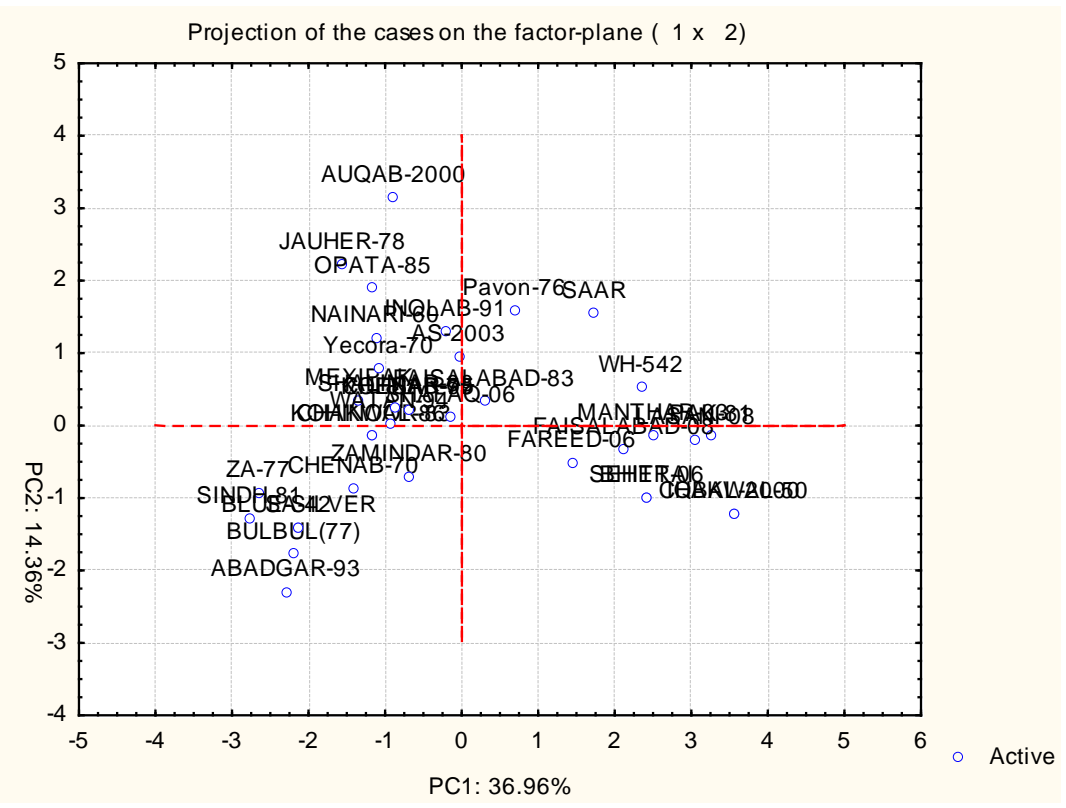

Figure 4. PCA scatter plot based on pedigree data.

The SSR based PC1 and PC2 showed narrow genetic diversity confirming the presence of few dominating parents (Figure 3). The principal component analysis on the basis of dominant parents in pedigrees depicted more scattered diversity pattern (Figure 4). The division of pre and post 2000 varieties was also clear. The comparison of Figure 1 and Figure 2 represented a clear difference in SSR and pedigree based diversity patterns. This type of difference between genetic diversity estimates between AFLP and pedigree data were also reported by Barrett et al., [9] and Soleimani et al., [10]. In these most cited findings, the extent of pedigree based genetic distance was greater than that based on AFLP data.

\section{Conclusion}

The results from this research rejected all null hypotheses and accepted alternate hypotheses. Hence, 1) parents in the pedigree of Pakistani wheat varieties are not randomly used; 2) Pakistani wheat varieties have not substantially broad genetic base; 3) SSR and pedigree data do not provide similar pattern of genetic diversity. Comparing results of different genetic diversity estimation methods may be indicative of their utility as parental selection tools for plant breeders. Reduction in diversity caused by intensive selection can be counterbalanced by introgression of novel germplasm. Parents from winter wheat, A, B and D synthetic derivatives will help breeders to develop stable varieties with broader genetic base and adaptability.

\section{References}

[1] Sajjad, M., Khan, S.H. and Khan, A.S. (2011) Exploitation of Germplasm for Grain Yield Improvement in Spring Wheat (Triticum aestivum). International Journal of Agriculture and Biology, 13, 695-700.

[2] Cox, T.S., Murphy, J.P. and Rodgers, M.D. (1986) Changes in Genetic Diversity in the Red Winter Wheat Region of the United States. Proceedings of the National Academy of Sciences of the United States of America, 83, 5583-5586. http://dx.doi.org/10.1073/pnas.83.15.5583

[3] Rehman, A., Sajjad, M., Khan, S.H., Peña Bautista, R.J. and Khan, N.I. (2014) Lower Tendency of Allelic Variation of Glu Genes and Absence of 1BL-1RS Translocation in Modern Pakistani Wheats. Cereal Research Communications, 42, 139-150. http://dx.doi.org/10.1556/CRC.2013.0050

[4] Sajjad, M., Khan, S.H., Maqbool, R., Ather, A. and Iqbal, N. (2012) Selection of Pakistani and CIMMYT Wheat Lines for Better Grain Yield and Quality. International Journal of Agriculture and Biology, 14, 645-649.

[5] Kumar, B., Lal, G.M.R. and Upadhyay, A. (2009) Genetic Variability, Diversity and Association of Quantitative Traits with Grain Yield in Bread Wheat (Triticum aestivum L.). Asian Journal of Agricultural Sciences, 1, 4-6.

[6] Tahir, M., Turchelta, T., Anarw, R. and Lafiandra, D. (1996) Assessment of Genetic Variability in Hexaploid Wheat 
Landraces of Pakistan Based on Polymorphism for High Molecular Weight Glutenin Subunits. Genetic Resources and Crop Evolution, 43, 211-220. http://dx.doi.org/10.1007/BF00123273

[7] Maric, S., Bede, M., Martincic, J. and Guberac, V. (1998) Variability of Some Winter Wheat Traits from Breeding Process. Sjemenarstvo, 15, 421-433.

[8] Martin, J.M., Talbert, L.E., Lannings, S.P. and Blake, N.K. (1995) Hybrid Performance in Wheat as Related to Parental Diversity. Crop Science, 35, 104-108. http://dx.doi.org/10.2135/cropsci1995.0011183X003500010019x

[9] Barrett, B.A. and Kidwell, K.K. (1998) Comparison of AFLP and Pedigree-Based Genetic Diversity Assessment Methods Using Wheat Cultivars from the Pacific Northwest. Crop Science, 38, 1271-1278. http://dx.doi.org/10.2135/cropsci1998.0011183X003800050026x

[10] Soleimani, V.D., Baum, B.R. and Johnson, D.A. (2002) AFLP and Pedigree-Based Genetic Diversity Estimates in Modern Cultivars of Durum Wheat [Triticum turgidum L. Subsp. Durum (Desf.) Husn.]. Theoretical and Applied Genetics, 104, 350-357. http://dx.doi.org/10.1007/s001220100714

[11] Sajjad, M., Khan, S.H., Qadir, M., Rasheesd, A., Kazi, A.M. and Khan, I.A. (2014) Association Mapping Identifies QTLs on Wheat Chromosome 3A for Yield Related Traits. Cereal Research Communication, 42, 177-188. http://dx.doi.org/10.1556/CRC.2013.0061

[12] Gulnaz, S., Sajjad, M., Khaliq, I., Khan, A.S. and Khan, S.H. (2011) Relationship among Coleoptile Length, Plant Height and Tillering Capacity for Developing Improved Wheat Varieties. International Journal of Agriculture and Biology, 13, 130-133.

[13] Rogowsky, P.M., Guidet, F.L.Y., Langridge, P., Shepherd, K.W. and Koebner, R.D.M. (1991) Isolation and Characterization of Wheat-Rye Recombinants Involving Chromosome Arm 1DS of Wheat. Theoretical and Applied Genetics, 82, 537-544. http://dx.doi.org/10.1007/BF00226788

[14] Thomas, J. and Michael, P. (2010) Statistica. In: Salkind, N., Ed., Encyclopedia of Research Design, SAGE Publications, Inc., Thousand Oaks, 1443-1445. http://dx.doi.org/10.4135/9781412961288.n441 
Scientific Research Publishing (SCIRP) is one of the largest Open Access journal publishers. It is currently publishing more than 200 open access, online, peer-reviewed journals covering a wide range of academic disciplines. SCIRP serves the worldwide academic communities and contributes to the progress and application of science with its publication.

Other selected journals from SCIRP are listed as below. Submit your manuscript to us via either submit@scirp.org or Online Submission Portal.
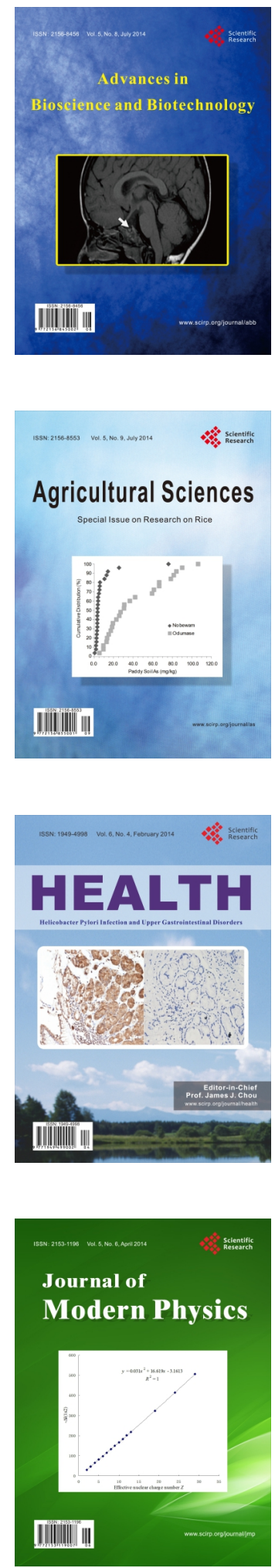
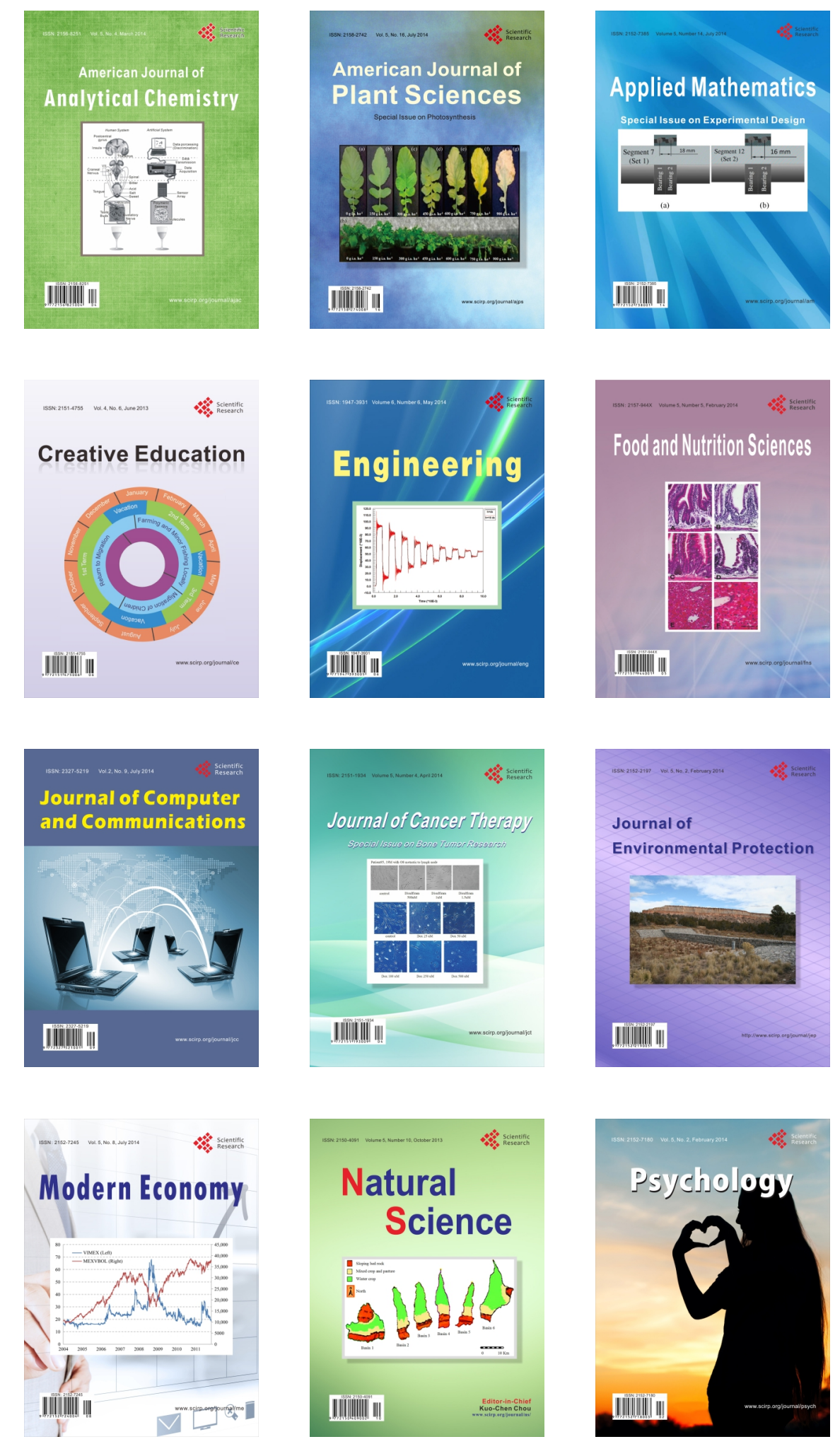